Original Article

\title{
Use of Internet among Rural Teenagers: Pattern of Usages, Awareness and Associated Health Hazards
}

\author{
*Jobayer $\mathrm{M}^{1}$, SultanaR 2 , Anwar $\mathrm{SS}^{3}$, Afroz $\mathrm{Z}^{4}$, Akter $\mathrm{N}^{5}$, Chowdhury $\mathrm{M}^{6}$, Rashed $\mathrm{A}^{7}$, FarhanaN ${ }^{8}$, \\ Islam LMT $^{9}$, Hussain $\mathrm{DA}^{10}$
}

\begin{abstract}
Internet has become an essential tool for communication, information, and entertainment and use of internet is increasing among the teenage group. This cross sectional study was conducted among 385 teenagers from rural area of Narayanganj district in Bangladesh to evaluate the practice of internet use, their awareness about the beneficial and harmful effects and associated physical and psychological health hazards. The study reached its various findings from the view point of rural area of our country. The study population was chosen purposively; data were collected using a semi structured questionnaire regarding their knowledge and various practice of internet use relating to the objectives. Most of the respondents were students and came from lower middle class family. Majority of the study people recently started to use internet and
\end{abstract}

*1. Dr. Mohammad Jobayer, Medical Officer, Department of Microbiology, Dhaka Medical College, Dhaka, Bangladesh. Phone: 01716042561; Email: mjobayerk52@yahoo.com

2. Dr. Rabeya Sultana, Assistant Professor, Institute of Epidemiology, Disease Control \& Research, Dhaka, Bangladesh

3. Dr. Sk Serjina Anwar, Medical Officer, Infectious Disease Hospital, Dhaka, Bangladesh.

4. Dr Zeenat Afroz, Lecturer, Department of Microbiology, Dhaka Medical College, Dhaka, Bangladesh

5. Dr. Nadira Akter, Lecturer, Department of Microbiology, Dhaka Medical College, Dhaka, Bangladesh.

6. Dr. Mahbuba Chowdhury, Lecturer, Department of Microbiology, Dhaka Medical College, Dhaka, Bangladesh.

7. Dr. Asif Rashed, Nasreen Farhana, Lecturer, Department of Microbiology, Dhaka Medical College, Dhaka, Bangladesh.

8. Dr. Nasreen Farhana, Clinical Pathologist, Department of Microbiology, Dhaka Medical College, Dhaka, Bangladesh.

9. Dr. Lohani Md Tazul Islam, Medical Officer, Department of Cardiology, Bangabandhu Sheikh Mujib Medical University, Dhaka, Bangladesh.

10. Dr. Dewan Azmal Hussain, Assistant Professor, National Institute of Diseases of Chest and Hospital, Dhaka, Bangladesh.

* For correspondence they were mostly light or moderate user in terms of time spending. Mobile phone was used as device by $84.7 \%$ people for their internet browsing. Teenagers used internet mainly for entertainment (42.1\%) and social networking (35.6\%) purpose and not much for learning or education. They were aware about the beneficial and the harmful effects of internet use especially abuses. Commonly experienced physical health hazards by them were headache (11.7\%), straining of eyes or blurring of vision (10.7\%) and skipping meals or change in eating behavior (9.1\%), and among the psychological hazards, restlessness or agitation (8\%) and depression (5.2\%) were stated. It may be concluded that use of internet among teenagers of rural area of our country is at modest level associated with a few health hazards but the merits of internet based networking is yet to be revealed by them.

Key words: Use of internet, rural teenagers, health hazards.

\section{INTRODUCTION}

Internet has become an important tool for social interaction, sharing information and entertainment. ${ }^{1}$ As internet has moved into homes, schools and businesses, there has been a rapidly growing public awareness of potential adverse effects arising from excessive, maladaptive or addictive internet usage. ${ }^{2,3}$ As an important period between childhood and adulthood, teenage is encompassed by alterations in physical, psychological and social development. ${ }^{4}$ Presence of relatively immature cognitive control makes this period a time of vulnerability and adjustment ${ }^{5,6}$ and may lead to a higher incidence of affective disorders and addiction among teenagers. ${ }^{7.8}$

Total internet user in Bangladesh in 2016 is 21,439,070 which are $13.2 \%$ of population and $0.6 \%$ share of world internet users. ${ }^{9}$ Importance of internet is increasing here for communicative purposes among adults, but teenagers are also very frequent users. Teenagers are spending long hours on social networking sites and this has resulted in a significant drop in regular healthy social interaction and affecting school and home life. Scope of play out of doors is virtually non-existent for children and most of them spend time 
indoors and much of it is lonely time watching television or using internet. Passing time is a popular activity on Facebook as one can play games, chat, and network. Increased internet use results in less physical, psychological, and emotional outlets for stimulation necessary for development.

Misuse of Facebook by teenagers has become one of the most insidious menaces of the society. When a teenager spends too much time on the internet, their behavior patterns can be adversely altered as they spend less time on studies and household responsibilities. High-risk internet users have inappropriate dietary behavior which could result in stunted growth and development. ${ }^{10}$ Those who regard themselves as dependent on internet often report high levels of depressive symptoms. ${ }^{11}$

Educating teenagers and parents is an important step for effective and safe use of internet. In recent studies, many reported that role of internet in completion of school projects is vital, and online resources have replaced need for library visits. ${ }^{12,13}$ Internet also plays an important role in how adolescents educate themselves about specific health matters. ${ }^{14}$ They regularly use internet to gather information on news, sports and other areas of personal interest. There is a tremendous range of information available online with respect to sexuality that ranges from information on sexual health resources to online pornography and some others misuses. ${ }^{15}$

Internet users in Bangladesh have increased much these days and the importance of internet is enormous especially to teenagers. They are spending long hours on internet. For these reasons, this study was carried out to reveal the real scenario of knowledge and practice of internet use among teenage people in rural area Bangladesh.

\section{MATERIALS AND METHODS}

This cross sectional study was conducted during November, 2016. It was carried out in rural area of Rupganj upazila under Narayanganj district. Six bangla medium schools with co-education (both male and female students) and two other common gathering places of the rural area of Rupganj were purposively selected for this study. Through non-probability sampling 385 respondents were selected. From each school 50 students of 13 to 18 years of age from different classes (class VII-X) who used internet by any device were included.

A self-administered questionnaire containing information on socio-demographic indicators, quality of life, internet usage and level of knowledge and awareness about internet were filled in. The following socio-demographic characteristics were obtained: age, gender, educational level and self-reported family economy. Internet usage pattern was assessed by examining the frequency of internet use per day and week and the purpose of internet use. Collected data were classified according to characteristics and various statistical methods and 'Microsoft Excel' software were used for analysis.

\section{RESULTS}

Age of the respondents was between 13 to 18 years. Among them $211(54.81 \%)$ were male and male to female ratio was 1:0.82. (Table-I)

Table-I: Age and sex distribution of the study population $(n=385)$.

\begin{tabular}{|l|c|c|c|}
\hline Age (year) & Male & Female & Number n(\%) \\
\hline 13 & 14 & 15 & $29(7.53)$ \\
\hline 14 & 45 & 43 & $88(22.84)$ \\
\hline 15 & 53 & 45 & $98(25.85)$ \\
\hline 16 & 56 & 46 & $102(26.49)$ \\
\hline 17 & 21 & 19 & $40(10.39)$ \\
\hline 18 & 22 & 6 & $28(7.27)$ \\
\hline Total & 211 & 174 & $385(100)$ \\
\hline
\end{tabular}

About $85 \%$ of the teenagers used mobile phone as their device for the internet use and rest of them used laptop or desktop in home and cyber café. (Figure-1)

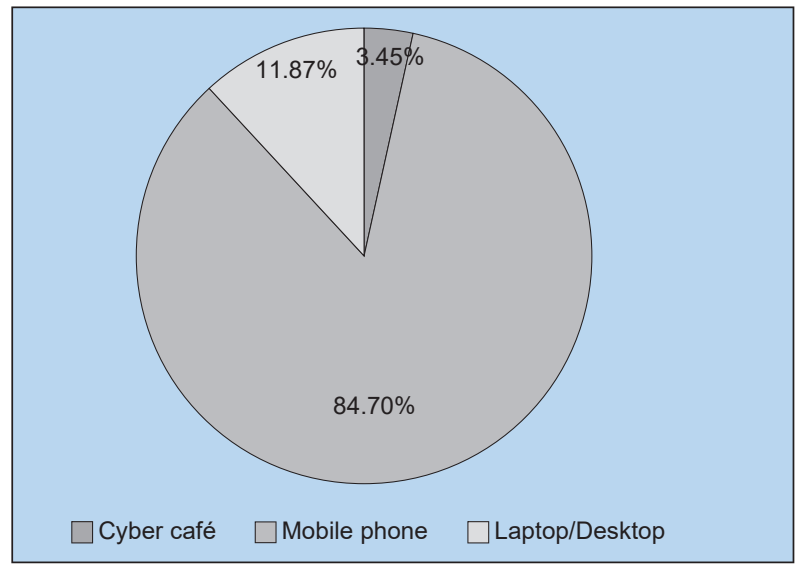

Figure-1: Pattern of devices for internet use $(n=385)$.

Among the respondents $55.06 \%$ were 'moderate' users of internet in terms of time they spent daily or weekly. Overall $14 \%$ were 'heavy users' who spent more than four hours per day; among them $20.4 \%$ were male and $6.3 \%$ female and the difference between male and female heavy internet user was statistically significant. (Table-II) 
Table-II: Distribution of study population according to frequency of internet use. ( $n=385)$

\begin{tabular}{|l|c|c|c|c|}
\hline Category of user & Male $\mathbf{n}(\%)$ & Female $\mathbf{n}(\%)$ & Total $\mathbf{n}(\%)$ & P value \\
\hline Light (few times/week) & $51(24.17)$ & $68(39.08)$ & $119(30.91)$ & P value- 0.00162 \\
\hline Moderate (few times/day) & $117(55.45)$ & $95(54.60)$ & $212(55.06)$ & P value- 0.8670 \\
\hline Heavy (>4 hours/day) & $43(20.38)$ & $11(6.32)$ & $54(14.03)$ & P value- 0.00007 \\
\hline
\end{tabular}

Chi-square test was done to measure the level of significance.

Common purposes of internet use were entertainment (42.1\%) and social networking (35.6\%) whereas 9.9\% teenagers used internet for educational purpose. (Table-III)

Table-III: Purpose of internet use (according to type of sites visited).

\begin{tabular}{|l|c|c|c|}
\hline Purpose & $\begin{array}{c}\text { Male } \\
\mathbf{n}(\%)\end{array}$ & $\begin{array}{c}\text { Female } \\
\mathbf{n}(\%)\end{array}$ & $\begin{array}{c}\text { Total } \\
\mathbf{n}(\%)\end{array}$ \\
\hline Entertainment & $97(45.9)$ & $65(37.4)$ & $162(42.1)$ \\
\hline Social networking & $51(24.2)$ & $86(49.4)$ & $137(35.6)$ \\
\hline Gaming & $39(18.5)$ & $09(5.2)$ & $48(12.5)$ \\
\hline Education & $24(11.4)$ & $14(8.0)$ & $38(9.9)$ \\
\hline
\end{tabular}

According to the respondents, keeping communication (49.10\%) and making new relationship (27.01\%) were the best positive side of internet use and addiction to internet $(52.99 \%)$ and waste of time $(25.19 \%)$ were the common demerits for them. (Table-IV)

Table-IV: Perception of merits and demerits of internet among study population.

\begin{tabular}{|l|c|c|}
\hline Merits of internet use & Number & Percentage \\
\hline Communication & 189 & 49.10 \\
\hline Making new relationship & 104 & 27.01 \\
\hline Entertainment & 51 & 13.25 \\
\hline Education & 28 & 7.27 \\
Others & 13 & 3.37 \\
Demerits of internet use & & \\
\hline Addiction to internet & 204 & 52.99 \\
\hline Waste of time & 97 & 25.19 \\
\hline Less concentration in study & 62 & 16.11 \\
\hline Others & 22 & 5.71 \\
\hline
\end{tabular}

Headache was the most commonly (11.69\%) experienced physical health hazard during internet use, followed by straining of eyes or blurring of vision (10.65\%) and among psychological hazards restlessness or agitation (8.05\%) and depression $(5.19 \%)$ were most common. (Table-V)

Table-V: Different types of health hazard experienced by teenagers during internet uses.

\begin{tabular}{|c|c|c|c|}
\hline Health hazards & Male & Female & $\begin{array}{l}\text { Total } \\
\text { n(\%) }\end{array}$ \\
\hline \multicolumn{4}{|l|}{ Physical hazards } \\
\hline Headache & 36 & 09 & 45 (11.69) \\
\hline $\begin{array}{l}\text { Straining of eyes or } \\
\text { blurring of vision }\end{array}$ & 29 & 12 & $41(10.65)$ \\
\hline $\begin{array}{l}\text { Skipping meal or change } \\
\text { in eating pattern }\end{array}$ & 26 & 09 & $35(9.09)$ \\
\hline Less sleep or insomnia & 21 & 12 & $33(8.57)$ \\
\hline Less physical activity & 18 & 11 & $29(7.53)$ \\
\hline \multicolumn{4}{|l|}{ Psychological hazards } \\
\hline Restlessness/ agitation & 19 & 12 & $31(8.05)$ \\
\hline Depression & 11 & 09 & $20(5.19)$ \\
\hline Loneliness & 07 & 11 & $18(4.68)$ \\
\hline Damaging relationship & 04 & 08 & $12(3.12)$ \\
\hline
\end{tabular}

\section{DISCUSSION}

While there are certainly concerns about the growth of technology and internet use among teenagers in Bangladesh and around the world, technology should not be necessarily negative. The fact is that technology has become an integral part of the life of the modern teenager.

Among the 385 rural teenage respondents most were students of different classes of secondary school level and maximum came from lower middle income group. They 
started using internet in recent time and about $85 \%$ of them used mobile phone as their device for internet use and in majority cases (91\%) their parents were the providers of the expenditure. The availability of mobile phone to the teenagers may have facilitated the use of internet in rural setting of our country as most of the rural area is not under cover of broad band networking of internet.

The teenagers were categorized as 'Heavy, Moderate and Light' user according to the time they spent daily or weekly on internet. ${ }^{10}$ Heavy users who spent more than four hours per day on internet comprised about $14 \%$ of the respondents; among them male were predominant and more than half of the respondents were moderate users of internet spending less than 4 hours but visited internet few times per day. Excessive internet use or uncontrollable use of internet is regarded as internet addiction or pathological internet use. ${ }^{16,17}$

Main purpose of use of internet among teenagers in this study was entertainment (42.1\%) and social networking; on the other hand less than one in ten teenagers used internet for their learning or educational purpose. Remarkably about half of the female respondents used internet for only social networking that means Facebook; whereas among male it was $24 \%$. In contrast, a study in Canada showed that many of the young users searched internet for educational purpose like solving homework, completing assignments and answering questions or sometimes topics for health education. ${ }^{14}$ This inconsistency between the purpose of internet use probably is due to the differences between socio-economical statuses of two study groups.

The teenagers were aware about the beneficial and harmful affects of internet use especially internet abuses. They mentioned that keeping communication with friends and making new relationship were the most beneficial sides of internet for them whereas addiction to internet and wastage of time were the most damaging ones. It is not always a waste of time to hang out online and sometimes it is found that spending time online is good for young people to pick up social and technical skills they need to be competent citizens in the digital age. ${ }^{18}$

Time spent online affects psychological well-being and increment in this time decreases social integration which negatively affects psychological well-being. ${ }^{19,20}$ Teenage respondents were asked to mention any physical or psychological health hazards they had experienced during time being online. The most commonly experienced physical health hazards they reported were headache, straining or blurring of eyes during internet use and occasional skipping of meals or change in eating pattern and behavior; among the psychological hazards restlessness or agitation and depression were most common. These symptoms were in accordance with findings of several studies who mentioned that heavy internet use is associated with mood disorders, such as depression and various adverse health outcomes like poor sleeping quality and lower level of physical activity. ${ }^{10,21}$ There is relationship between obesity and screen time, which is related to sedentary lifestyle and also snacking and decreased sleep time. ${ }^{22}$

Technology is not a good or a bad thing. With proper usage and supervision from adults, teenagers can take advantage of many great learning opportunities on internet. If parents leave children unsupervised, it can result in internet addiction, depression, cyber-bullying, and unwanted predators taking advantage of unsuspecting teenagers. Parents should become more conscious and aware as well as responsible for monitoring online usage of their children. They should recognize that technology is now a normal part of many teenagers' lives.

Among some limitations of the study; data were collected from a small sample and as the study area was limited to seven villages, the result may not represent the whole rural teenage population of the country. The overall knowledge awareness and practice of internet among teenagers could not be addressed completely. Few persons of less or no schooling were involved so that the information did not reflect the real picture of rural average teenagers.

\section{CONCLUSIONS}

In the information age, internet use is becoming increasingly significant in acquisition of information and knowledge. Internet use is now considered to form a part of the culture of teenagers, and hence studying internet use and its merits as well as demerits is important to create a sound teenage culture. Teenagers of Bangladesh should be taken under cover of various awareness programmes for better understanding of the positive and negative aspects of internet use and abuses.

\section{REFERENCES}

1. Tsitsika A, Critselis E, Kormas G, Filippopoulou A, Tounissidou D, Freskou A, et al. Internet use and misuse: a multivariate regression analysis of the predictive factors of internet use among Greek adolescents. Eur J Pediatr. 2009; 168: 655-65. 
2. Block JJ. Issues for DSM-V: internet addiction. Am J Psychiatry. 2008; 165: 306-7.

3. Cooney GM and Morris J. Time to start taking an internet history? Br J Psychiatry. 2009; 194: 185-7.

4. Ernst M, Pine DS, Hardin M. Triadic model of the neurobiology of motivated behavior in adolescence. Psychol Med. 2006; 36: 299-312.

5. Casey BJ, Tottenham N, Liston C, Durston S. Imaging the developing brain: what have we learned about cognitive development? Trends Cogn Sci. 2005; 9: 104-10.

6. Galvan A, Hare TA, Parra CE, Penn J, Voss H, Glover G, et al. Earlier development of the acumens relative to orbitofrontal cortex might underlie risk-taking behavior in adolescents. J Neurosci. 2006; 26: 685-92.

7. Steinberg L. Cognitive and affective development in adolescence. Trends Cogn Sci. 2005; 9: 69-74.

8. Grant JE, Potenza MN, Weinstein A, Gorelick DA. Introduction to behavioral addictions. Am J Drug Alcohol Abuse. 2010; 36: 233-41.

9. Internet Live Stats. Elaboration of data by International Telecommunication Union (ITU), World Bank, and United Nations Population Division. Available from: www.InternetLive Stats.com.

10. Kim JH, Lau CH, Cheuk KK, Hui HLC, Kan P, Griffith SM. Brief report: Predictors of heavy internet use and associations with health promoting and health risk behaviors among Hong Kong university students. J Adolesc. 2010; 33: 215-20.

11. Morrison CM and Gore H. The relationship between excessive internet use and depression: a questionnaire based study of 1319 young people and adults. Psychopathol. 2010; 43: 121-6.

12. Stahl C and Fritz N. Internet safety: Adolescents' self-report. J Adolesc Health. 2002; 31: 7-10.

13. Lenhart A, Simon M, Graziano M. The internet and education: Findings of the Pew Internet $\&$ American
Life Project. [cited 2016 Dec 19]. Available from: http://www.pewinternet.org/pdfs/ PIP_Schools_ Report.pdf.

14. Media Awareness Network. Young Canadians in a Wired World-Phase II. [cited 2016 Jan 21]. Available from: http://www.mediaawareness.ca/english/ research/YCWW/phaseII/upload/YCWWII_Student_ Survey.pdf.

15. Kaiser Family Foundation Survey. Generation Rx.com: How young people use the internet for health information. [cited 2016 Dec 12]. Available from:http://www.kff.org/entmedia/upload/ Toplines.pdf.

16. Widyanto $\mathrm{L}$ and Griffiths $\mathrm{M}$. Internet addiction: a critical review. Int J Mental Health Addict. 2006; 4: 31-51.

17. Beard KW. Internet addiction: a review of current assessment techniques and potential assessment questions. Cyberpsychol Behavior. 2005; 8: 7-14.

18. Ito M. Hanging out, messing around and seeking out: kids living and learning with new media. The MacArthur Foundation. Cambridge, MA: MIT Press. 2008.

19. Van der Aa N, Overbeek G, Engels RCME, Scholte RHJ, Meerkerk GJ, Van den Eijnden RJJM. Daily and compulsive internet use and well-being in adolescence: a diathesis-stress model based on big five personality traits. J Youth Adolesc. 2009; 38: 765-76.

20. Weiser EB. The functions of internet use and their social and psychological consequences. Cyberpsychol Behavior. 2001; 4: 723-43.

21. An J, Sun Y, Wan Y, Chen J, Wang X, Tao F. Associations between problematic internet use and adolescents' physical and psychological symptoms: possible role of sleep quality. J Addict Med. 2014; 8: 282-7.

22. Fu K, Chan WSC, Wong PWC, Yip PSF. Internet addiction: prevalence, discriminant validity and correlates among adolescents in Hong Kong. Br J Psychiatry. 2010; 196: 486-92. 